\title{
Perceived Parenting Styles and their Impact on Depressive Symptoms in Adolescent 15-18 Years Old
}

\author{
Brunilda Laboviti
}

\author{
Doi:10.5901/jesr.2015.v5n1p171
}

\begin{abstract}
Previous studies have been focused in their examination of the relationship between perceived parenting styles and depressive symptoms adolescent 15-18 years. The literature suggests that depressive symptoms may be caused by adolescent the negative social experience and persons who are involved in these experiences. Some features in the formation of adolescent personality may represent vulnerability for depression, especially in terms of dysfunctional parenting. The aim of the research is the measurement, description, study of perceived parenting styles of adolescents themselves and linkages with the symptoms of depression in teens as well as analysis of the relationship between them. Measuring instruments that were used in this research were, Parental Authority Questionnaire (PAQ) which was supplemented by an instrument with 30 teenagers and statements that can be used simultaneously for both the mother and father. Another instrument Depression Scale for Children (CES - DC). The rate of depression CES - D was used for the first time by Lenore Radloff while she was requesting scientific and worked at the National Institute of Mental Health.These questionnaire were completed by 100 adolescents $15-18$ years. This is a correlation study, which attempts to reveal the relationship between two variables that appear in the research questions. In this study is found that there is a meaningful relation between parenting style and depressive symptoms and parenting style specifically to authoritative. Much more perceived as authoritative parent, as mother and father, even less, will report depressive symptoms adolescents in this study.
\end{abstract}

Keywords: parenting style, authoritative parenting style, adolescent ,depressive symptoms .

\section{Introduction}

Adolescence, the transitory period between the childhood and grown up age coincides with the physical, cognitive, social changes etc. while the teenagers are faced with these changes, they build self-concept, which somehow is the meaning of themselves. Two significant elements of self-concept are self-assessment and control. Numerous studies have shown that self-assessment and control are defense to many stressors. The same, a positive self-concept is related to self-care, cooperation with medical care and participation to activities. As a result, a positive self-concept during adolescence can influence not only to mental health but even on the physical one. Considering that adolescence coincides with passing from nine years school to high school, where the individual is faced with many challenges and adaptations, these changes especially at ages 13,14 years old can generate troubles in self-concept. The researchers have argued that people with a strong self-concept have copying strategies which are more oriented to the problem than to the emotions, comparing with the others, especially seen to females. This factor is significant for a better physical and mental health development. The emotional support is also important for all teenagers, males and females as well.

\section{Examination of Bibliography}

\section{Summary of findings from bibliography}

Since a lot of time there was the opinion that the relationship parent-child is an important factor in development of child and psychological welfare. The researches have constantly found relations between parenting styles during adolescence and development of depressive symptoms. The bibliography suggests that parents who adopt an authoritative style (Maccoby \& Martin, 1983), so parents who settle clear limits as they keep an open and warm position have children who show less depressive symptoms Amato, P. R., \& Flower, F. (2002). Baumrind (1971) pretends that this is a balance between warmth and establishment of structure which is the one that gives more positive results for children with authoritative parents, including a more positive variety of behaviors and emotions. The authoritative parenting style is very important during the period of adolescence where the teenagers test their limits, ask for their independence and at the same time need support, acceptance and supervision (Baumrind, 1971). For example the authoritarian parenting style is in contrast with the authoritarian style of low warmth levels with very much restriction, 
structured strictly, indulgent which is typical for its high level of warmth and absence of structure or low one, or with a style which lack them both warmth and structure too.

Adolescence is a phase of development characterized from the process of forming an independent identity and the self sense (Erikson, 1968). The process of development of a positive self sense is affected by a series of influence sphere (Fletcher, A. C., \& Jefferies, B.C. (1999) including the climate created from parents making so self development of teenagers inseparable from parenting behaviors. This way, placing self in a positive sense is the frame inside which a series of other development duties will be performed in adolescence and it is directly related to psychological welfare (Meeus, 1996). Due to the importance of development of a positive self sense and stable one during adolescence and the relation with emotional welfare and parenting, the process of self development can serve as a means through which an authoritative parenting style affects on depression in adolescence. Different researchers have examined the relationship between the parenting style and depression in adolescence (Aunola et al., 2000; Garber et al., 1997; Ge et al., 1996; Greaven et al., 2000). The recent researchers have processed the concept of parenting styles examining a specific behavior like: parenting inclusion, care, refusal, hostility, cohesion and defense. For example using parenting styles of Baumrind Radziszewska et al. (1996) and Aunola et al. (2000) it was found that authoritative parenting style is related to lower depressive symptoms levels in adolescence, while the high levels of depressive symptoms are related to a non inclusive parenting style. The researchers also have examined on parenting defense as a non-authoritative parenting style. Mcfarlane et al. (1995), Rey (1995) reported that higher is the parenting defense much higher results to be the depression level in adolescence. The depression is classified as the fourth reason that takes to death and incapability in the world. Adolescence is one of the most critic moments of depression development starting at 14.7 years old for females and 15.4 years old for males. So, the good understanding of risk factors that foresee the development of this disorder and the defending factors is essential in order to contribute to prevention and treatment of depression in adolescence. Though it is used a wide range of methods to measure the depression in adolescence including here selfreporting instruments of symptomatology and assessments for clinic diagnosis, findings for sample of teenagers have been relatively stable. Research have shown that a parenting style where dominate the absence of affection and individual differences in temperament are a significant factor for development of depression in adolescence Nunley.K.F(2001).

Many of researches about parents and teenagers have been focused on impact of parenting styles. Theory of selfdetermination suggests that parenting which supports autonomy, which has a high inclusion and structure, is associated with more positive psychosocial results. Parents who support autonomy to children encourage them to make their choices without pressuring or reward to control their behavior. Parental involvement includes parenting interest and knowledge about life of their children. The structure refers to the extent in which parents allow rules and clear expectancies for their children, and constant leading. Children and teenagers whose parents are high in these three dimensions report less depression and other interior symptoms, higher self assessment and higher competence to perceive in several fields Heaven, P., Newbury, K., \& Mak, A. (2004). Otherwise parents who are low in these three dimensions have their children with more externalized and internalized symptoms including the depressive ones.

Research have demonstrated strong evidence regarding parenting style and the results of mental health in adolescence (Baumrind, 1991) concluded that parental over control is accompanied by high levels of depressive symptomatology. Rey.J.M (1995) examined the effect of various parenting styles on depression of teenagers and antisocial behaviors and compared it with the environmental and genetic influence. Robertson, J. F., \& Simons, R.L. (1989) researched if parenting styles are related to motivation of child, to level of depression, to problematic behavior and self assessment. It was found a positive connection between parenting styles and depression levels. Forehand, R., \& Nousiainen, S. (1993) realized a study where authoritative parents had positive results for kids and teenagers. The conclusion was that teenagers who perceived parenting style as authoritative had high results in self efficiency and low ones in depression.

\section{Method of Study}

This study is realized through a quantitative research which refers to numerical measurements and to specific aspects of phenomena. This sort of research is a deductive one which is based on theory and in this case the support from theory and findings from reference are a significant part for attestation of research studying questions. In this case it was used the quantitative research and not the qualitative one referring to goal of study which is: To explore the possible link between depressive symptoms and perceived parenting styles, to reveal the typical link for quantitative research. The data analysis does not reveal the causes and consequences because this is a quantitative descriptive and not 
experimental research. In this survey, the representative samples are the teenagers randomly chosen at high schools of Tirana city. The questionnaires were filled at premises of high schools.

\subsection{Research questions}

Is there any relation between the perceived parenting styles and depressive symptoms?

Teenagers who perceive the authoritative parenting style, do they present a lower depression symptoms level in adolescence?

\subsection{Measuring instruments used in this research except the demographic information are:}

Parental Authority Questionnaire (PAQ) which was filled by teenagers is a shorter variant of Buri's Parental Authority Questionnaire (PAQ), an instrument with 30 statements and which could be used at the same time for mother and father as well. This instrument is built basing on model of Baumrind's (1971) that speaks about authoritative, authoritative and liberal parenting model.

Depression Scale for Children (CES-DC). Depression scale CES-D was used for the first time by Lenore Radloff as she was a scientific researcher and worked for the National Institute of Mental Health. Almost $85 \%$ of teenagers who are diagnosed with depression after a very deep and structured interview will take high points and this is a measuring instrument as well. However, $20 \%$ of teenagers who report high points at this questionnaire do not obligatorily demonstrate the other part of symptoms as query to meet the clinic conditions to be diagnosed with major depression. Radloff, L.S. (1977) 'The CES-D scale: A self report depression scale for research in the general population. Applied Psychological Measurement, 1: 385-401.

\subsection{Sampling}

Participants in this survey are 100 teenagers of age: $25 \%$ or 25 teenagers are 15 years old, $25 \%$ or 25 teenagers are 16 years old, $30 \%$ or 30 teenagers are 17 years old and $20 \%$ or 20 teenagers are 18 years old. The number of samples involved in this survey is 100 participants. The gender in this sample was represented by 54 females or $54 \%$ of sample is females and $46 \%$ of sample or 46 persons are males. In this survey, the representative sample will be the teenagers randomly chosen by high schools of Tirana city. The survey was performed in three high schools of Tirana city the classes taken in study were the school courses 10,11 and $12^{\text {th }}$ years. For every year were taken 2-3 parallel courses, this was done to have a wide variety. The selection of subjects was random, keeping the gender balance.

\section{Results of Study}

In this study it has been found that there is a meaningful relation between the parenting style and depressive symptoms and actually with authoritative parenting style. More a parent is perceived as authoritative like mother like father, less depressive symptoms would be reported in that survey. The same these results are based on many studies respectively by Nunley.K.F(2001) who realized a study where the authoritative parents concluded to be accompanied with positive results for kids and teenagers. It was found that the teenagers who perceived parenting style as authoritative had high points in self efficiency and low ones in depression. Many from researches on parents and teenagers are focused on impact of parenting styles. This means more authoritative is the parent perceived less depressive symptoms will teenagers report.

In this way the focus of this study was exactly the teenagers of high schools who belonged to age group 15-18 years old, where the average age was properly 16. 4 while the standard deviation is SD= 1.07661 whereas the distribution of result regarding the age has been: $25 \%$ or 25 teenagers are 15 years old, $25 \%$ or 25 teenagers are 16 years old, $30 \%$ or 30 teenagers are 17 years old and $20 \%$ or 20 teenagers are 18 years old. So we can say that the distribution of results was already equal for any group in order to have the reports kept in way that they do not have any forms of mistakes. The number of sample involved in studies was 100 participants. The gender in this sample was represented by 54 females or $54 \%$ of sample was females and $46 \%$ of sampling or 46 persons were males. From interactions between gender and reporting of depressive symptoms we can say that the value of $X 2(1)=22.069$ where $p<0.001$ thus there is a significant statistical difference between the gender and demonstration of depressive symptoms. In this case girls have more depressive symptoms than males in CED instrument. This is supported even from findings of 
the other researchers Mounts, N. S. (2002). He states that there is a prevalence of female teenagers who report more depressive symptoms than males.

Table 1: Distribution of results for depressive symptoms shown by teenagers.

Depressive symptoms

\begin{tabular}{|l|c|c|c|c|}
\hline & Frequency & Percentage & Valid percentage & Accumulated percentage \\
\hline Do not show depressive symptoms & 70 & 70.0 & 70.0 & 70.0 \\
Validity Show depressive symptoms & 30 & 30.0 & 30.0 & 100.0 \\
$\quad$ Total & 100 & 100.0 & 100.0 & \\
\hline
\end{tabular}

Table 2: Descriptive presentation of averages and standard avoidance of points in parenting style.

\begin{tabular}{|l|c|c|c|c|c|}
\hline & $\mathrm{N}$ & Minimum & Maximum & Average & Standard avoidance \\
\hline Authoritative parenting style & 100 & 27.00 & 111.00 & 51.9104 & 8.97529 \\
Authoritarian parenting style & 100 & 16.00 & 62.00 & 38.9528 & 9.63001 \\
Liberal parenting style & 100 & 13.00 & 52.00 & 31.0802 & 7.96189 \\
Authoritative mother parent style & 100 & 16.00 & 35.00 & 26.1840 & 4.25481 \\
Authoritative father parent style & 100 & 7.00 & 81.00 & 25.7264 & 6.34480 \\
Authoritarian father parent style & 100 & 7.00 & 32.00 & 19.8726 & 5.80144 \\
Liberal father parent style & 100 & 7.00 & 29.00 & 16.1981 & 4.94983 \\
Authoritarian mother parent style & 100 & 6.00 & 29.00 & 15.5708 & 4.79036 \\
Liberal mother parent style & 100 & 6.00 & 26.00 & 14.8821 & 4.35621 \\
Valid N & 100 & & & & \\
\hline
\end{tabular}

Table 3: Distribution of results for depressive symptoms demonstrated by teenagers and perceived style of father and mother parenting style together

\begin{tabular}{|c|c|c|c|c|c|}
\hline \multicolumn{6}{|c|}{ Correlation } \\
\hline & & $\begin{array}{c}\text { Depressive } \\
\text { symptoms }\end{array}$ & $\begin{array}{l}\text { Authoritative } \\
\text { parent style }\end{array}$ & $\begin{array}{c}\text { Authoritarian } \\
\text { parent style }\end{array}$ & \begin{tabular}{|c} 
Liberal parent \\
style
\end{tabular} \\
\hline \multirow{3}{*}{$\begin{array}{l}\text { Depressive } \\
\text { symptoms }\end{array}$} & Pearson correlation & 1 & $-.416^{* *}$ & $.276^{* *}$ & .051 \\
\hline & Sig. (2-parts) & & .000 & .000 & .461 \\
\hline & $\mathrm{N}$ & 212 & 212 & 212 & 212 \\
\hline \multirow{3}{*}{$\begin{array}{l}\text { Authoritative } \\
\text { parent style }\end{array}$} & Pearson correlation & $-.416^{* *}$ & 1 & -.127 & $-.199^{* k}$ \\
\hline & Sig. (2-parts) & .000 & & .065 & .004 \\
\hline & $\mathrm{N}$ & 212 & 212 & 212 & 212 \\
\hline \multirow{3}{*}{$\begin{array}{l}\text { Authoritarian } \\
\text { parent style }\end{array}$} & Pearson correlation & $.276^{\star *}$ & -.127 & 1 & -.045 \\
\hline & Sig. (2- parts) & .000 & .065 & & .510 \\
\hline & $\mathrm{N}$ & 212 & 212 & 212 & 212 \\
\hline \multirow{3}{*}{$\begin{array}{l}\text { Liberal parent } \\
\text { style }\end{array}$} & Pearson correlation & .051 & $-.199^{* k}$ & -.045 & 1 \\
\hline & Sig. (2- parts) & .461 & .004 & .510 & \\
\hline & $\mathrm{N}$ & 212 & 212 & 212 & 212 \\
\hline
\end{tabular}

The tables as above show that the demonstration of depressive symptoms is linked significantly with level $p<0,001$ and $p<0.05$ for authoritative parenting style and for authoritarian parenting style as well, exactly with values $r=-.416$ and $r=. .276$. The same the value of relation for liberal parenting style has a negative direction but the relation is not significant and it is weakly presented at level $r=0.051$. So the depressive symptoms are related with more than one of parenting styles in way how teenagers perceive their parenting style for mother and father. This result is valid for the summarized styles of both parents. 
Tablea 4:

\begin{tabular}{|c|c|c|c|c|c|c|}
\hline \multicolumn{3}{|c|}{ Depressive symptoms R } & $\begin{array}{c}\text { Depressive } \\
\text { symptoms }\end{array}$ & $\begin{array}{l}\text { Authoritative } \\
\text { parent style }\end{array}$ & $\begin{array}{l}\text { Authoritarian } \\
\text { parent style }\end{array}$ & $\begin{array}{c}\text { Liberal } \\
\text { parent style }\end{array}$ \\
\hline \multirow{2}{*}{$\begin{array}{l}\text { Do not } \\
\text { demonstrate } \\
\text { depressive } \\
\text { symptoms }\end{array}$} & \multirow[t]{2}{*}{$\begin{array}{l}\text { Depressive } \\
\text { symptoms }\end{array}$} & $\begin{array}{l}\text { Pearson correlation } \\
\text { Sig. (2- parts) } \\
\mathrm{N}\end{array}$ & $\begin{array}{l}1 \\
70 \\
\end{array}$ & $\begin{array}{c}-.278^{* *} \\
.001 \\
70 \\
\end{array}$ & $\begin{array}{l}.016 \\
.854 \\
70 \\
\end{array}$ & $\begin{array}{l}.294^{+4} \\
.001 \\
70 \\
\end{array}$ \\
\hline & & & & & & \\
\hline \multirow{4}{*}{$\begin{array}{l}\text { Demonstrate } \\
\text { depressive } \\
\text { symptoms }\end{array}$} & $\begin{array}{l}\text { Depressive } \\
\text { symptoms }\end{array}$ & $\begin{array}{l}\text { Pearson correlation } \\
\text { Sig. (2- parts) } \\
\mathrm{N} \\
\end{array}$ & $\begin{array}{r}1 \\
30 \\
\end{array}$ & $\begin{array}{c}\frac{-.404^{* *}}{.000} \\
30 \\
\end{array}$ & $\begin{array}{c}.207 \\
.059 \\
30 \\
\end{array}$ & $\begin{array}{l}-.189 \\
.085 \\
30 \\
\end{array}$ \\
\hline & $\begin{array}{l}\text { Authoritative } \\
\text { parent style }\end{array}$ & $\begin{array}{l}\text { Pearson correlation } \\
\text { Sig. (2- parts) } \\
\mathrm{N}\end{array}$ & $\begin{array}{c}-.404^{* *} \\
.000 \\
30 \\
\end{array}$ & $\begin{array}{r}1 \\
30 \\
\end{array}$ & $\begin{array}{c}-.314^{*+} \\
.004 \\
30 \\
\end{array}$ & $\begin{array}{l}-.129 \\
.242 \\
30 \\
\end{array}$ \\
\hline & $\begin{array}{l}\text { Authoritarian } \\
\text { parent style }\end{array}$ & $\begin{array}{l}\text { Pearson correlation } \\
\text { Sig. (2- parts) } \\
\mathrm{N}\end{array}$ & $\begin{array}{l}.207 \\
.059 \\
30\end{array}$ & $\begin{array}{c}.314^{*+*} \\
.004 \\
30\end{array}$ & $\begin{array}{l}1 \\
30\end{array}$ & $\begin{array}{l}. .122 \\
.269 \\
30 \\
\end{array}$ \\
\hline & $\begin{array}{l}\text { Liberal parent } \\
\text { style }\end{array}$ & $\begin{array}{l}\text { Pearson correlation } \\
\text { Sig. (2- parts) } \\
\text { N }\end{array}$ & $\begin{array}{c}-.189 \\
.085 \\
30 \\
\end{array}$ & $\begin{array}{c}-.129 \\
.242 \\
30 \\
\end{array}$ & $\begin{array}{c}-.122 \\
.269 \\
30 \\
\end{array}$ & 1 \\
\hline
\end{tabular}

The presentation of profound processing in this table shows that in every case the perceived parenting style is linked significantly with depressive symptoms even when they are in moderated levels or in low ones. Though this link is not strong it is still a factor that impacts on demonstration of these symptoms especially in case of authoritative parenting style which in every case is negatively related to these symptoms.

In the same way research has shown strong evidence considering the parenting style and results of mental health in adolescence (Baumrind, 1991). Rey.J.M (1995) found that the parenting over control is accompanied with high levels of depressive symptomatology. Rey examined the effect of various parenting styles in depression of teenagers and antisocial behaviors and compared it with the environmental and genetic influence.

The theory of self determination Heaven, P., Newbury, K., \& Mak, A. (2004), suggested that parenting that supports autonomy that has a high involvement and structure, is accompanied with more positive psychosocial results. Parents who support autonomy in kids encourage them to make their choices or give them rewards to control their behavior. The parental involvement includes parental interest and knowledge about life of their kids. The structure refers to the extent in which parents give rules and clear expectancy for their children, and constant guide. Children and teenagers whose parents are high in these dimensions report less depression and other interior symptoms, higher self assessment and higher competence perceived in several fields Heaven et al. (2004). Otherwise parents who are low in these three dimensions have their children with more externalized and internalized symptoms, including depressive ones. Heaven et al. (2004). Depression is classified as the fourth cause that takes to death and incapability in the world. Adolescence is one of the most critic moments for depression development starting at 14.7 years old for girls and 15.4 years old for boys Lamborn, S. D., Mounts, N.S., Steinberg, L., \& Dornbusch, S.M. (1991). Baumrind Radziszeëska et al. (1996) and Aunola et al. (2000) found that the authoritative parenting style is related to very low levels of depressive symptoms in adolescence, while the high levels of depressive symptoms are related to a non inclusive parenting style. Researchers have also examined on parenting over protection as a non authoritative parenting style. Mcfarlane et al. (1995), Rey (1995), reported that higher is the parenting over protection higher is the scale of depression in adolescence. The parenting style includes the relation between parents and children that contains respect or lack of respect for child. It can be warm and consolidated or can be disorganized. He can force the child to behave well or he can show respect for independence of his child. According to (Baumrind 1966) the way how parents behave with child is considered a parenting style. The definition of meaning about parenting style for the goal of study will be: the way how parents grow up their child. It is clear that parents use various parenting styles in different times, and in different circumstances. Maybe parenting styles are influenced by temperament of parents and quality of their relation with children. It is believed that there is an emotional climate for relation parent-child. The emotional climate has a significant influence on behave of child and on his personality. This important detail which propounds that lack of affection and mutual relationship useful between child and parent brings emotional and behavioral problems to children. When parents support their children they 
ease him adaptation with environment and increase him the motivation. This also takes to growth of their competence and control over the world and increases the skills of child to adjust his behave. Vice versa the parenting style that controls the behaviour of child inducts to him feelings that success and fail are on the other hands more than on theirs. And so they undermine the motivation and behavior of competence in child. Baumrind (1971).

\section{Conclusions}

All the goal and research questions of this paperwork are realized concluding in principal findings by their attestation through statistical analysis from where the relevant results came from. More authoritative is the parent conceived father or mother less depressive symptoms are reported from teenagers in that survey. Moreover, basing on findings it was concluded that the teenagers who conceived parenting style as authoritative had higher points in self efficiency and lower in depression. This means that more authoritative parent is conceived less depressive symptoms report their teenagers.

The authoritative parenting style is kind, careful to children but with clear restrictions to them and try to keep children in predictable premises. The authoritative parenting style has the most positive effects for the early social development of children. Children of authoritative parents are usually more curious, more independent and more responsible which was proved even in this study.

\section{References}

Amato, P. R., \& Flower, F. (2002). Parenting practices, child adjustment, and family diversity. Journal of Marriage and the Family, 64(3), 703716

Aunola, K., Stattin, H., \& Nurmi, J-E. (2000). Parenting styles and adolescents' achievement strategies. Journal of Adolescence, 23, $205-222$. Baumrind, D. (1966). Effects of authoritative parental control on child behavior. Child Development, 37, 857-907.

Baumrind, D. (1971). Current patterns of parental authority. Developmental Psychology, 4(1Pt 2), 1-102.

Erikson, E. H. (1968). Identity: Youth and crisis. New York: Norton.(10-50)

Fletcher, A. C., Steinberg, L., \&Williams-Wheeler, M. (2004). Parental Influences on 47 Adolescent Problem Behavior: Revisiting Stattin and Kerr. Child Development, 75(3), 781-796.

Forehand, R., \& Nousiainen, S. (1993). Maternal and Paternal Parenting: Critical Dimensions in Adolescent Functioning. Journal of Family Psychology, 7(2), 213-221.

Garber, J., Robinson, N.S.,\& Valentiner, D. (1997). The relation between parenting and adolescent depression: Self-worth as a mediator. Journal of Adolescent Research, 12, 12-33.

Ge, X., Best, K.M., Conger, R.D., \& Simons, R.L. (1996). Parenting Behaviors and the Occurrence and Co-Occurrence of Adolescent Depressive Symptoms and Conduct Problems. Developmental Psychology, 32(4), 717-731.

Greaven, S. H., Santor, D.A., Thompson, R., \& Zuroff, D.C. (2000). Adolescent Self- Handicapping, Depressive Affect, and Maternal Parenting Styles. Journal of Youth and Adolescence, 29(6), 631-646.

Heaven, P., Newbury, K., \& Mak, A. (2004). The impact of adolescent and parental characteristics on adolescent levels of delinquency and depression. Personality and Individual Differences, 36, 173-185.

Lamborn, S. D., Mounts, N.S., Steinberg, L., \& Dornbusch, S.M. (1991). Patterns of Competence and adjustment among adolescents from authoritative, authoritarian, indulgent, and neglected families. Child Development, 62, 1049-1065

Meeus, W. (1966)Identity Development, Parental and Peer Support in Adolescence: Results of a National Dutch Survey .102-135

Maccoby, E., \& Martin, J. (1983). Socialixation in the context of the family: Parent child interaction. In P. H. Mussen (Ed.), Handbook of Child Psychology (Vol. 4, pp. 1-100).New York: Wiley.

McFarlane, A. H., Bellissimo, A., \& Norman, G.R. (1995). Family Structure, Family Functioning and Adolescent Well-Being: the Transcendent Influence of Parental Style.

Journal of Child Psychology and Psychiatry and Allied Disciplines, England, 36(5), 847- 864.

Mounts, N. S. (2002). Parental Management of Adolescent Peer Relationships in Context: The Role of Parenting Style. Journal of Family Psychology, 16(1), 58-69. National Center for Health Statistics (1999). Healthy People 2000 Review, 1998-99.

Nunley, K. F. (2001). The Relationship of Self-Esteem and Depression In Adolescence. Retrieved 78-100 November 5, 2003, from http://www.help4teachers.com/depression.htm49

Radziszewska, B., Richardson, J.L., Dent, C.W., \& Flay, B.R. (1996). Parenting style and Adolescent Depressive symptoms, Smoking, and Academic Achievement: Ethnic, Gender, and SES Differences. Journal of Behavioral Medicine, 19(3), 289-305.

Rey, J. M. (1995). Perceptions of poor maternal care are associated with adolescent depression. Journal of Affective Disorders, 34, 95-100.

Robertson, J. F., \& Simons, R.L. (1989). Family factors, self-esteem, and adolescent depression. Journal of Marriage and the Family, 51(1), 125-138

Radloff, L.S. (1977) 'The CES-D scale: A self report depression scale for research in the general population'. Applied Psychological Measurement 1: 385-401.

Steinberg, L., Elmen, D.J., \& Mounts, N.S. (1989). Authoritative parenting, psychosocial maturity, and academic success amoung adolescents. Child Development, 60, 1424-1436. 50 